\title{
DNA Conjugation by the Staudinger Ligation: New Thymidine Analogues
}

\author{
Anna Baccaro, Samuel H. Weisbrod, Andreas Marx* \\ Department of Chemistry, Chair of Organic Chemistry \& Cellular Chemistry, University of Konstanz, 78457 Konstanz, Germany \\ Fax +49(7531)885140; E-mail: Andreas.Marx@uni-konstanz.de
}

Dedicated to Prof. Dr. Wolfgang Pfleiderer on the occasion of his $80^{\text {th }}$ birthday

\begin{abstract}
Two novel modified 2'-deoxyuridine triphosphates carrying an azide functionality linked to the nucleobase were synthesized. For probing the sterical influence on enzymatic incorporation and Staudinger ligation, differently sized flexible linkers were chosen. Both nucleotides can completely replace natural thymidine in primer extension as well as polymerase chain reaction (PCR) using Pyrococcus woesei DNA polymerase. For PCR with larger gene fragments as template, however, the longer linker disturbs the DNA polymerase and yields less product. For azide-labeled primer extension products, subsequent conjugation of suitably functionalized phosphines via Staudinger ligation was achieved, for example for the conjugation of biotin as an affinity tag.
\end{abstract}

Key words: azides, conjugation, Staudinger ligation, DNA, nucleotides

To enable investigation of complex biological systems, efficient labeling techniques for the involved biopolymers are often required. Conjugation of functional molecules like dyes or affinity tags to these biopolymers allows further and better investigations of such systems. Ideally, the coupling reaction has to be site-specific, bioorthogonal, high yielding, and for in vivo experiments biocompatible and nontoxic. There is no standard conjugation protocol which fulfills all of these conditions so far. ${ }^{1}$

Recently, two promising reactions based on the reactivity of the azide moiety were reported. ${ }^{2}$ One method makes use of the $[2+3]$ cycloaddition reaction of an azide and an alkyne first reported by Huisgen. ${ }^{3}$ Copper catalysis promotes the reaction to proceed at room temperature ${ }^{4}$ and led to widespread applications especially in bioconjugate chemistry. ${ }^{5}$ Recently, the method has been extended for conjugation of DNA. ${ }^{6,7}$ On the other hand, the so-called Staudinger ligation developed by Bertozzi readily occurs between an azide and a phosphine without the need for further reagents. ${ }^{8}$ The intermediate aza-ylide gets thereby trapped by an acyl group to form a stable amide bond. This reaction has been applied, for example, in the conjugation of carbohydrates, protein and phage particles, peptide ligation, and immobilization. ${ }^{9}$ Few examples for the conjugation of DNA by Staudinger ligation are known. The conjugation of a fluorescence dye to the $5^{\prime}$ terminus of single stranded DNA ${ }^{10}$ as well as the sequence specific conjugation of phenanthroline to DNA for subsequent $\mathrm{Cu}(\mathrm{I})$-induced strand scission has been reported. ${ }^{11,12} \mathrm{Re}$ - cently, we presented the synthesis of 7-azide-modified 7deaza-2'-deoxyadenosine, its incorporation in a growing DNA strand by enzymatic primer extension reaction, and subsequent biotin labeling by Staudinger ligation. ${ }^{13}$ Here, we report the synthesis of two new azide-modified thymidine analogues with different linker lengths and their conversion into triphosphates. Their incorporation into DNA was then investigated using primer extension reactions as well as PCR and the resulting DNA was subsequently conjugated with biotin using Staudinger ligation.

Our strategy to label DNA site-specifically involves two steps (Scheme 1): First the azide-modified triphosphate should replace the corresponding natural 2 -deoxynucleoside- $5^{\prime}$ - $O$-triphosphate (dNTP) in a DNA polymerase reaction. For this the polymerase has to accept the unnatural nucleoside and ideally can use it as a template for incorporation of the canonical base in PCR. Then the obtained azide-labeled DNA should serve as substrate for further modifications by Staudinger ligation with a suitably functionalized phosphine. Since it has been shown that 5-modified thymidine derivatives are accepted by DNA polymerases, ${ }^{7,14,15}$ we focused our synthesis on these kinds of analogues. A sterically encumbered moiety might disturb the acceptance of the DNA polymerase; however, a short linker might decrease the yield of the subsequent Staudinger ligation. So we designed two nucleotides bearing a flexible linker with different lengths towards the azide moiety to test which is best suited for our endeavor (4a and $\mathbf{4 b}$, Scheme 2).

The synthesis started with a Sonogashira reaction from fully TBS protected 5-iodo-2'-deoxyuridine 1 with two different unprotected alkynyl alcohols (pent-4-yn-1-ol or $O$-propargyl triethylene glycol) to afford the different linker lengths (Scheme 2). ${ }^{16}$ The alcohols 2 were then converted into the mesylates and afterwards substituted with $\mathrm{NaN}_{3}$ to form the azides 3. After deprotection of the hydroxyl groups of the sugar moiety, the corresponding $5^{\prime}$ triphosphates 4 were obtained using the reported methods. ${ }^{17}$ The yields of each step were high in both cases, but overall slightly lower for the nucleoside bearing the triethylene glycol linker.

With these triphosphates in hand, we next investigated the properties of $4 \mathrm{a}$ and $\mathbf{4 b}$ towards their action on DNA polymerases. In order to test the ability of DNA polymerases to accept the modified triphosphates and to incorporate the respective nucleotide into a nascent DNA strand, we set up a primer extension reaction. A 35-nucleotide (nt) template was designed in a way to contain a single A res- 

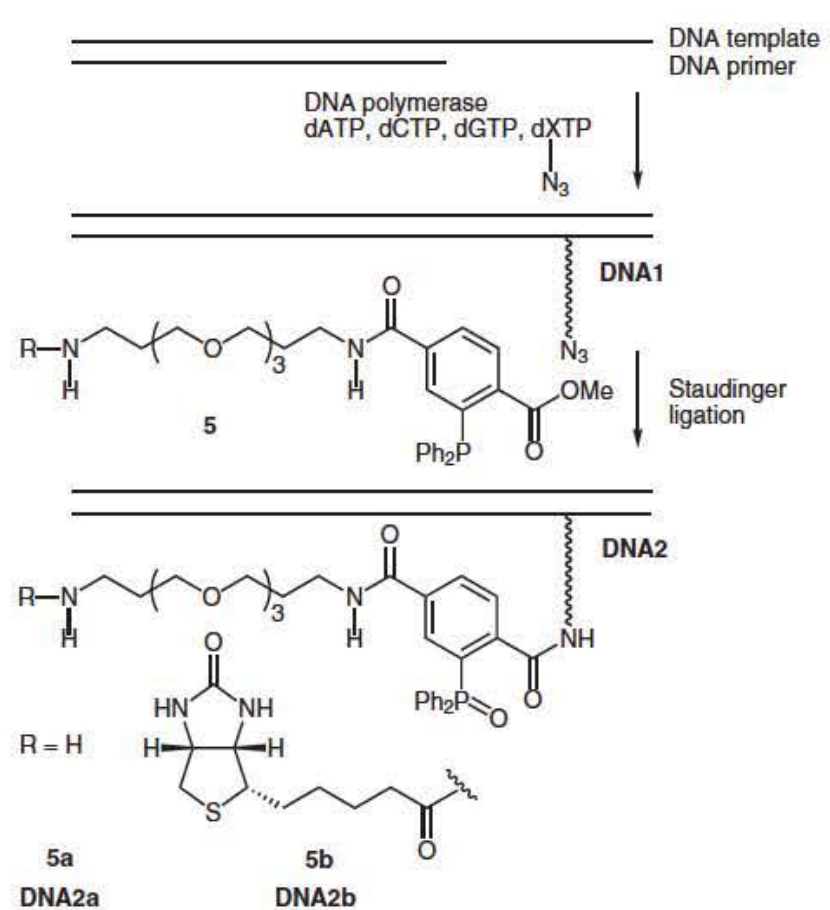

Scheme 1 Schematic depiction for labeling of DNA with phosphines $\mathbf{5} \mathbf{a}$ and $\mathbf{5 b}$.

idue, coding for insertion of a modified dTTP analogue after extending the 23 nt primer strand by three residues (Figure 1A). The reactions were analyzed by denaturing polyacrylamide gel electrophoresis (PAGE). We tested Thermus aquaticus (Taq), Thermococcus litoralis [Vent (exo-)] and Pyrococcus woesei (Pwo) DNA polymerase, whereas $P$ wo DNA polymerase accepted the modified triphosphates best as has been reported by us ${ }^{13}$ and Famulok et al. for generation of highly functionalized DNA. ${ }^{14}$ Reactions lacking dTTP predominantly abort before the template A after extension by three nucleotides, while reactions including dTTP gave rise to full-length products (Figure 1B). In case of substitution of natural dTTP by $4 a$ or $4 \mathrm{~b}$ full-length product was also obtained in a similar fashion. However, the reaction product is somewhat shifted on the gel due to its higher molecular weight and therefore lower mobility in the polyacrylamide gel.

Next, we investigated whether the double-stranded enzymatically synthesized azide-labeled DNA is suitable for Staudinger ligation. First the temperature dependence was

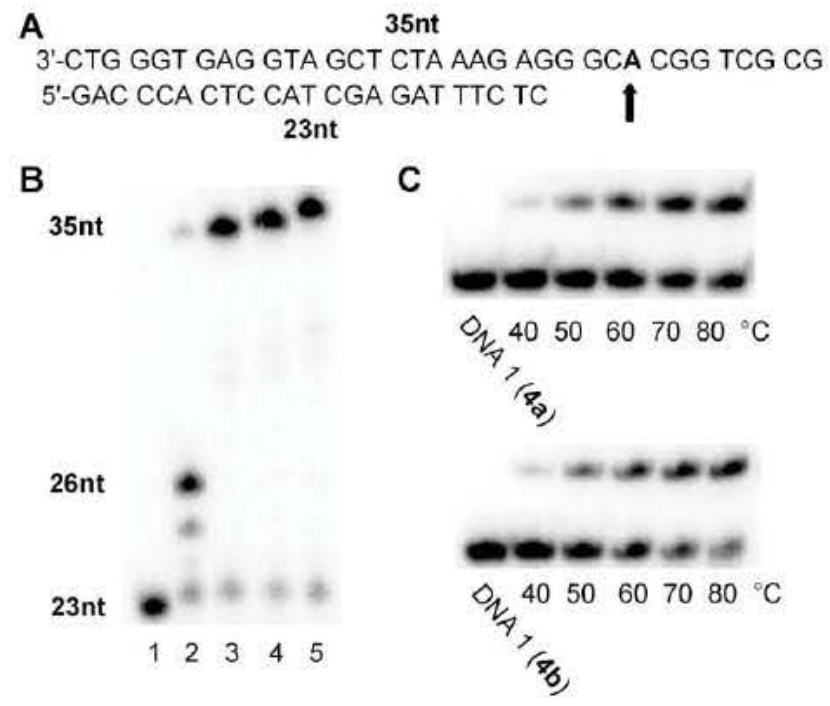

Figure 1 (A) Sequences of primer template complex used to study incorporation of modified triphosphates $4 a$ and $4 b$. (B) Denaturing PAGE analysis of primer extension reactions. Lane 1: $5^{\prime}-{ }^{32} \mathrm{P}$-labeled 23nt primer strand; Lane 2: primer template complex including dATP, dCTP, dGTP, and Pwo DNA polymerase; Lane 3: same as in lane 2 including dTTP; Lane 4: same as in lane 2 including 4a; Lane 5: same as in lane 2 including $4 \mathbf{b}$. (C) Staudinger ligation employing enzymatically synthesized double-stranded DNA (dsDNA) as shown in Figure 1B lane 4 (upper autoradiogram) or lane 5 (lower autoradiogram) with $25 \%$ DMF in aqueous buffer and phosphine 5 a at various temperatures as indicated. $\mathrm{nt}=$ nucleotide.

studied using phosphine $\mathbf{5 a}$ as a model (Figure 1C). ${ }^{11}$ The ligation reaction was carried out in aqueous buffer with $25 \%$ of DMF to increase the solubility of the phosphine compound. Increasing temperatures led to higher conversion within four hours reaction time. Interestingly, DNA derived from building block $4 \mathrm{~b}$ formed the reaction product in higher yields compared to 4a. However, best results were obtained after increasing reaction time to 12 hours at $60{ }^{\circ} \mathrm{C}$. For further ligation experiments we used phosphine $\mathbf{5 b}$ bearing a biotin at its end. Biotin is often used in biochemistry for labeling issues and can be further conjugated with streptavidin functionalized materials. ${ }^{18}$ In this reaction, again, DNA with building block $4 \mathrm{~b}$ generated higher yields (70\%) than $4 a(60 \%$, Figure $2 \mathrm{~A}$ ). The yield was determined by quantifying the radioactivity of both the product and starting material DNA bands on the polyacrylamide gel by conventional phosphorimaging.

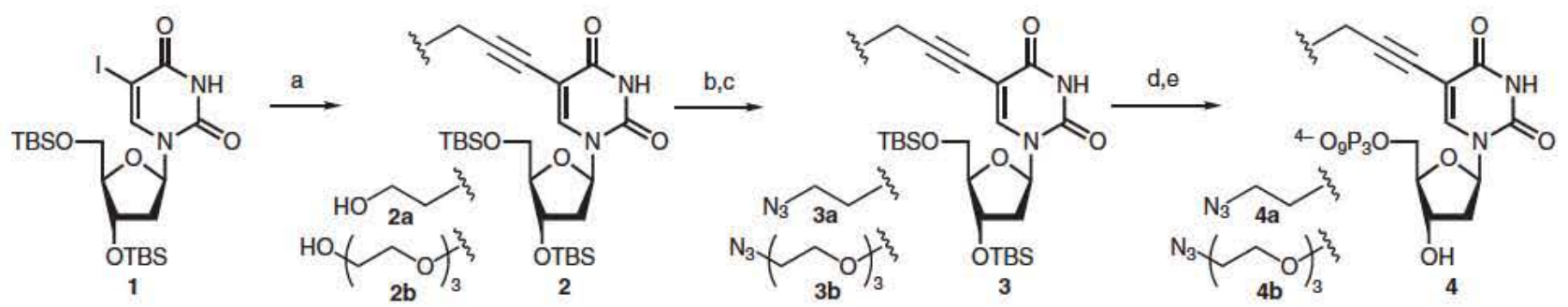

Scheme 2 Synthesis of azide modified triphosphates. Reagents and conditions: $\mathrm{Et}_{3} \mathrm{~N}, \mathrm{CuI}, \mathrm{Pd}\left(\mathrm{PPh}_{3}\right)_{4}, \mathrm{DMF}, 20{ }^{\circ} \mathrm{C}, 2 \mathrm{a}: \mathrm{pent}-4-\mathrm{yn}-1-\mathrm{ol}, 81 \%$, 2b: $O$-propargyl triethylene glycol, $83 \%$; (b) $\mathrm{MsCl}$, DIPEA, $\mathrm{CH}_{2} \mathrm{Cl}_{2}, 0^{\circ} \mathrm{C}$; (c) $\mathrm{NaN}_{3}$, DMF, $35^{\circ} \mathrm{C}, 3 \mathrm{a}$ : $70 \%$ over 2 steps, $3 \mathrm{~b}: 50 \%$ over 2 steps; (d) TBAF, THF, $0{ }^{\circ} \mathrm{C}$; (e) proton sponge, $\mathrm{POCl}_{3}, \mathrm{PO}(\mathrm{OMe})_{3}, 0{ }^{\circ} \mathrm{C}$, then $\left(\mathrm{Bu}_{3} \mathrm{NH}\right)_{2} \mathrm{H}_{2} \mathrm{P}_{2} \mathrm{O}_{7}, \mathrm{Bu}_{3} \mathrm{~N}$ then TEAB buffer, $4 \mathrm{a}: 28 \%$ over 2 steps, $4 \mathrm{~b}$ : $23 \%$ over 2 steps. 
A

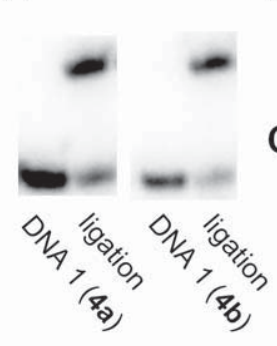

B

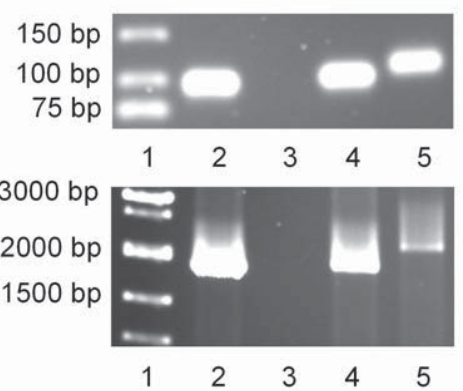

Figure 2 (A) Denaturing PAGE analysis of Staudinger ligation with phosphine 5b with $25 \%$ DMF for $12 \mathrm{~h}$ at $60{ }^{\circ} \mathrm{C}$ employing dsDNA, which contains $4 \mathbf{a}$ (left gel) or $\mathbf{4 b}$ (right gel). (B) 2.5\% agarose gel stained with ethidium bromide showing PCR products of $98 \mathrm{nt}$ template. Lane 1: Marker; Lane 2: PCR with dTTP; Lane 3: PCR without TTP; Lane 4: PCR with 4a instead of dTTP; Lane 5: PCR with $\mathbf{4 b}$ instead of dTTP. (C) $0.8 \%$ agarose gel stained with ethidium bromide showing PCR products of 1.9k nt template. Lanes as in Figure 2B. $\mathrm{nt}=$ nucleotide; $\mathrm{bp}=$ base pair

Finally, we tested the suitability of building blocks $4 \mathbf{a}$ and 4b for substituting dTTP in polymerase chain reactions (PCR). In this case we only tested $P$ wo DNA polymerase, first with a short template of $98 \mathrm{nt}$ in size. As with the primer extension tests we conducted one control reaction with all four natural dNTPs leading to a single PCR product with the desired length. In another control we performed the same reaction in the absence of dTTP leading to no observable PCR product formation (Figure 2B). Using standard PCR conditions the DNA polymerase was able to substitute compounds $\mathbf{4 a}$ and $\mathbf{4 b}$ for TTP and amplify the modified DNA in a similar fashion as with all four natural dNTPs. Again a small shift of the product bands to lower mobility was observed for the modified analogues, which is more pronounced with the larger modification of $\mathbf{4 b}$. Encouraged by these results we switched to a larger genomic DNA fragment as template for the PCR. Here, compound usage of $\mathbf{4 a}$ resulted in similar amounts of PCR product compared to the PCR with all natural dNTPs. PCR including compound $\mathbf{4 b}$ instead of dTTP produced less but observable product. Presumably the larger modification interfered with the DNA polymerase. Nevertheless only one PCR product was observed, and so we were able to generate large azide-labeled DNA fragments with both compounds.

In conclusion, a straightforward synthesis of azide modified thymidines was developed. The corresponding triphosphates were tested with different DNA polymerases indicating that $P$ wo DNA polymerase was most suited for our endeavor. Even amplification of large DNA fragments could be accomplished by PCR using this DNA polymerase and the modified triphosphates. The azide-labeled DNA in turn can be conjugated with phosphines that bear several functional groups, such as biotin. For Staudinger ligation reactions DNA generated by building block $\mathbf{4 b}$ seems to be superior over DNA derived from $4 \mathbf{a}$ due to smaller sterical hindrance. On the other hand, $\mathbf{4 b}$ leads to smaller PCR product formation, when amplifying large gene fragments with $\mathbf{4 b}$ instead of dTTP under standard reaction conditions. Further development of the reaction conditions might lead to improvements along these lines. However, Staudinger ligation with large azide-labeled DNA fragments could lead to some new applications in nanobiotechnology as well as material science.

All melting and boiling point values quoted are uncorrected. All reagents are commercially available and were used without further purification. TBS protected nucleoside $\mathbf{1},{ }^{19} \mathrm{O}$-tosyl triethylene glycol, ${ }^{20}$ and phosphines $\mathbf{5} \mathbf{a}$ and $\mathbf{5} \mathbf{b}^{11}$ were prepared according to literature. Solvents were stored over molecular sieves (Fluka) and used directly without further purification, unless otherwise noted. All reactions were conducted under rigorous exclusion of air and moisture. Elemental analyses were carried out by the microanalysis facility of the University of Konstanz. NMR spectra were recorded on a Jeol JNA-LA-400 $\left({ }^{1} \mathrm{H}: 400 \mathrm{MHz},{ }^{13} \mathrm{C}: 101 \mathrm{MHz},{ }^{32} \mathrm{P}: 162\right.$ $\mathrm{MHz})$, a Bruker Avance DRX $600\left({ }^{1} \mathrm{H}: 600 \mathrm{MHz},{ }^{13} \mathrm{C}: 151 \mathrm{MHz}\right)$. The solvent signals were used as references and the chemical shifts converted to the TMS scale and are given in ppm $(\delta)$. ESI-IT mass spectra were recorded on a Bruker Daltonics esquire 3000+. Flash chromatography was done using Merck silica gel G60 (230-400 mesh), and Merck precoated plates (silica gel $60 \mathrm{~F}_{254}$ ) were used for TLC. Both technical solvents were distilled prior to use. Petroleum ether (PE) used refers to the fraction boiling in the range $35-80{ }^{\circ} \mathrm{C}$.

\section{$O$-Propargyl Triethylene Glycol}

To a suspension of $\mathrm{NaH}$ (1.5 equiv, $0.69 \mathrm{~g}, 17.2 \mathrm{mmol}$ ) in THF (5 $\mathrm{mL}$ ), was added propargyl alcohol (1.5 equiv, $1.0 \mathrm{~mL}, 17.2 \mathrm{mmol}$ ) at $0{ }^{\circ} \mathrm{C}$. After $30 \mathrm{~min}$, a solution of $O$-tosyl triethylene glycol (1.0 equiv, $3.5 \mathrm{~g}, 11.5 \mathrm{mmol})$ in THF $(10 \mathrm{~mL})$ was added and the mixture stirred for $3 \mathrm{~h}$ at $0{ }^{\circ} \mathrm{C}$. Then it was combined with sat. aq $\mathrm{NaHCO}_{3}$ $(15 \mathrm{~mL})$ and extracted with EtOAc $(6 \times 10 \mathrm{~mL})$. The combined organic layers were dried $\left(\mathrm{MgSO}_{4}\right)$, and concentrated in vacuo. The residue was purified by flash chromatography [silica gel (EtOAc-

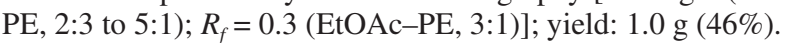

${ }^{1} \mathrm{H}$ NMR $\left(400 \mathrm{MHz}, \mathrm{CDCl}_{3}\right): \delta=2.43\left(\mathrm{t},{ }^{4} \mathrm{~J}=2.2 \mathrm{~Hz}, 1 \mathrm{H}, \mathrm{CH}\right)$, 3.57-3.64 (m, $\left.2 \mathrm{H}, \mathrm{CH}_{2} \mathrm{OH}\right), 3.64-3.75\left(\mathrm{~m}, 10 \mathrm{H}, \mathrm{OCH}_{2} \mathrm{CH}_{2} \mathrm{O}\right)$, $4.19\left(\mathrm{~d},{ }^{4} \mathrm{~J}=2.2 \mathrm{~Hz}, 2 \mathrm{H}, \mathrm{CCH}_{2} \mathrm{O}\right)$.

${ }^{13} \mathrm{C}$ NMR $\left(101 \mathrm{MHz}, \mathrm{CDCl}_{3}\right): \delta=58.2,61.5,68.9,70.1,70.2,70.5$, 72.4, 74.6, 79.5 .

ESI-MS: $m / z=211.0[\mathrm{M}+\mathrm{Na}]^{+}$.

\section{Compounds 2a and 2b; General Procedure}

To a solution of $\mathbf{1}$ (1.0 equiv) and $\mathrm{CuI}$ ( 0.2 equiv) in degassed DMF, were added with stirring the corresponding alkynol (2a: pent-4-yn1-ol, 2b: $O$-propargyl triethylene glycol, 3.0 equiv), $\left(\mathrm{PPh}_{3}\right)_{4} \mathrm{Pd}(0.1$ equiv) and $\mathrm{Et}_{3} \mathrm{~N}$ (2.0 equiv). The mixture was protected from light and stirred at r.t. (for $\mathbf{2 a}, 16 \mathrm{~h}$; for $\mathbf{2 b}, 18 \mathrm{~h}$ ). The mixture was combined with sat. aq $\mathrm{NaHCO}_{3}(10 \mathrm{~mL})$ and extracted with EtOAc $(3 \times 10 \mathrm{~mL})$. The combined organic layers were washed with brine $(10 \mathrm{~mL})$, dried $\left(\mathrm{MgSO}_{4}\right)$, and concentrated in vacuo. The residue was purified by flash chromatography.

\section{3',5'-Bis- $O$-(tert-butyldimethylsilyl)-5-(5-hydroxypent-1-ynyl)-} $2^{\prime}$-deoxyuridine (2a)

The reaction was carried out with deoxyuridine 1 (1.0 g, 1.72 mmol), CuI (65 mg, $0.34 \mathrm{mmol})$, pent-4-yn-1-ol (476 $\mu \mathrm{L}, 5.16$ $\mathrm{mmol}),\left(\mathrm{PPh}_{3}\right)_{4} \mathrm{Pd}(27 \mathrm{mg}, 0.17 \mathrm{mmol})$, and $\mathrm{Et}_{3} \mathrm{~N}(482 \mu \mathrm{L}, 3.43$ mmol) in DMF ( $5 \mathrm{~mL}$ ). Purification: silica gel (EtOAc-PE, 1:1 to $3: 2) ; R_{f}=0.3$ (EtOAc-PE, 3:2); yield: $750 \mathrm{mg}(81 \%)$.

${ }^{1} \mathrm{H}$ NMR $\left(600 \mathrm{MHz}, \mathrm{CDCl}_{3}\right): \delta=0.09\left(\mathrm{~s}, 3 \mathrm{H}, \mathrm{CH}_{3} \mathrm{Si}\right), 0.1(\mathrm{~s}, 3 \mathrm{H}$, $\left.\mathrm{CH}_{3} \mathrm{Si}\right), 0.15$ (s, $\left.3 \mathrm{H}, \mathrm{CH}_{3} \mathrm{Si}\right), 0.16\left(\mathrm{~s}, 3 \mathrm{H}, \mathrm{CH}_{3} \mathrm{Si}\right), 0.91$ (s, $9 \mathrm{H}, t-$ 
$\left.\mathrm{C}_{4} \mathrm{H}_{9} \mathrm{Si}\right), \quad 0.95 \quad\left(\mathrm{~s}, \quad 9 \quad \mathrm{H}, \quad t-\mathrm{C}_{4} \mathrm{H}_{9} \mathrm{Si}\right), \quad 1.77-1.86 \quad(\mathrm{~m}, \quad 2 \quad \mathrm{H}$, $\mathrm{CH}_{2} \mathrm{CH}_{2} \mathrm{CH}_{2} \mathrm{OH}$ ), 2.00-2.07 (m, 1 H, H-2'a), 2.31 (ddd, $\left.{ }^{2} J_{2^{\prime} \mathrm{b}, 2^{\prime} \mathrm{a}}=13.1 \mathrm{~Hz},{ }^{3} J_{2^{\prime} \mathrm{b}, 1^{\prime}}=5.7 \mathrm{~Hz},{ }^{3} J_{2^{\prime} \mathrm{b}, 3^{\prime}}=2.5 \mathrm{~Hz}, 1 \mathrm{H}, \mathrm{H}-2^{\prime} \mathrm{b}\right), 2.51$ (t, $\left.{ }^{3} \mathrm{~J}=6.8 \mathrm{~Hz}, 2 \mathrm{H}, \mathrm{CH}_{2} \mathrm{CH}_{2} \mathrm{CH}_{2} \mathrm{OH}\right), 3.76-3.81\left(\mathrm{~m}, 3 \mathrm{H}, \mathrm{H}-5^{\prime} \mathrm{b}\right.$, $\left.\mathrm{CH}_{2} \mathrm{CH}_{2} \mathrm{CH}_{2} \mathrm{OH}\right), 3.91\left(\mathrm{dd},{ }^{2} J_{5^{\prime} \mathrm{a}, 5^{\prime} \mathrm{b}}=11.4 \mathrm{~Hz},{ }^{3} J_{5^{\prime} \mathrm{a}, 4^{\prime}}=2.0 \mathrm{~Hz}, 1 \mathrm{H}\right.$, H-5'a), 3.97-3.99 (m, $\left.1 \mathrm{H}, \mathrm{H}-4^{\prime}\right), 4.40-4.43$ (m, $\left.1 \mathrm{H}, \mathrm{H}-3^{\prime}\right), 6.30$ (t, $\left.{ }^{3} J_{1^{\prime}, 2^{\prime} \mathrm{a}}={ }^{3} J_{1^{\prime}, 2^{\prime} \mathrm{b}}=5.7 \mathrm{~Hz}, 1 \mathrm{H}, \mathrm{H}-1^{\prime}\right), 7.93(\mathrm{~s}, 1 \mathrm{H}, \mathrm{H}-6), 8.28$ (br s, 1 $\mathrm{H}, \mathrm{NH})$.

${ }^{13} \mathrm{C}$ NMR (151 MHz, $\left.\mathrm{CDCl}_{3}\right): \delta=-4.5,-4.4,-3.8,-3.6,17.4,19.0$, $19.5,26.7,27.0,32.8,43.0,62.7,64.0,73.0,73.3,86.7,89.3,95.6$, 101.6, 142.5, 150.0, 162.7 .

ESI-MS: $m / z=561.5[\mathrm{M}+\mathrm{Na}]^{+}$.

Anal. Calcd for $\mathrm{C}_{26} \mathrm{H}_{46} \mathrm{~N}_{2} \mathrm{O}_{6} \mathrm{Si}_{2}: \mathrm{C}, 57.96 ; \mathrm{H}, 8.60 ; \mathrm{N}, 5.20$. Found: C, 57.98; H, 8.62; N, 5.14.

\section{3',5'-Bis-O-(tert-butyldimethylsilyl)-5-[12-hydroxy-(4,7,10-tri-} oxadodec-1-ynyl)]-2'-deoxyuridine (2b)

The reaction was carried out with deoxyuridine 1 ( $0.5 \mathrm{~g}, 0.86$ $\mathrm{mmol}), \mathrm{CuI}(33 \mathrm{mg}, 0.17 \mathrm{mmol}), O$-propargyl triethylene glycol (0.48 g, $2.50 \mathrm{mmol}),\left(\mathrm{PPh}_{3}\right)_{4} \mathrm{Pd}(13 \mathrm{mg}, 0.09 \mathrm{mmol})$, and $\mathrm{Et}_{3} \mathrm{~N}(242$ $\mu \mathrm{L}, 1.72 \mathrm{mmol})$ in DMF $(5 \mathrm{~mL})$. Purification: silica gel $\left(\mathrm{CH}_{2} \mathrm{Cl}_{2}-\right.$ $\mathrm{MeOH}, 20: 1) ; R_{f}=0.4\left(\mathrm{CH}_{2} \mathrm{Cl}_{2}-\mathrm{MeOH}, 20: 1\right)$; yield: $460 \mathrm{mg}$ $(83 \%)$.

${ }^{1} \mathrm{H}$ NMR $\left(400 \mathrm{MHz}, \mathrm{CDCl}_{3}\right): \delta=0.05\left(\mathrm{~s}, 3 \mathrm{H}, \mathrm{CH}_{3} \mathrm{Si}\right), 0.06(\mathrm{~s}, 3 \mathrm{H}$, $\left.\mathrm{CH}_{3} \mathrm{Si}\right), 0.10\left(\mathrm{~s}, 3 \mathrm{H}, \mathrm{CH}_{3} \mathrm{Si}\right), 0.11\left(\mathrm{~s}, 3 \mathrm{H}, \mathrm{CH}_{3} \mathrm{Si}\right), 0.86$ (s, $9 \mathrm{H}, t-$ $\left.\mathrm{C}_{4} \mathrm{H}_{9} \mathrm{Si}\right), 0.90\left(\mathrm{~s}, 9 \mathrm{H}, t-\mathrm{C}_{4} \mathrm{H}_{9} \mathrm{Si}\right), 1.99$ (ddd, ${ }^{2} J_{2^{\prime} \mathrm{a}, 2^{\prime} \mathrm{b}}=13.2 \mathrm{~Hz}$, $\left.{ }^{3} J_{2^{\prime} \mathrm{a}, 1^{\prime}}=7.5 \mathrm{~Hz},{ }^{3} J_{2^{\prime} \mathrm{a}, 3^{\prime}}=5.9 \mathrm{~Hz}, 1 \mathrm{H}, \mathrm{H}-2^{\prime} \mathrm{a}\right), 2.31\left(\right.$ ddd, $^{2} J_{2^{\prime} \mathrm{b}, 2^{\prime} \mathrm{a}}=13.0$ $\left.\mathrm{Hz},{ }^{3} J_{2^{\prime} \mathrm{b}, 1^{\prime}}=5.9 \mathrm{~Hz},{ }^{3} J_{2^{\prime} \mathrm{b}, 3^{\prime}}=2.5 \mathrm{~Hz}, 1 \mathrm{H}, \mathrm{H}-2^{\prime} \mathrm{b}\right), 3.57-3.77$ (m, 13 $\left.\mathrm{H}, \mathrm{H}-5^{\prime} \mathrm{b}, \mathrm{OCH}_{2} \mathrm{CH}_{2} \mathrm{O}\right), 3.87\left(\mathrm{dd},{ }^{2} J_{5^{\prime} \mathrm{a}, 5^{\prime} \mathrm{b}}=11.4 \mathrm{~Hz},{ }^{3} J_{5^{\prime} \mathrm{a}, 4^{\prime}}=2.5 \mathrm{~Hz}\right.$, $\left.1 \mathrm{H}, \mathrm{H}-5^{\prime} \mathrm{a}\right), 3.94-3.96$ (m, $\left.1 \mathrm{H}, \mathrm{H}-4^{\prime}\right), 4.34-4.39$ (m, 3 H, H-3', $\left.\mathrm{CH}_{2} \mathrm{O}\right), 6.27\left(\mathrm{t},{ }^{3} J_{1^{\prime}, 2^{\prime} \mathrm{a}}=7.5 \mathrm{~Hz},{ }^{3} J_{1^{\prime}, 2^{\prime} \mathrm{b}}=5.9 \mathrm{~Hz}, 1 \mathrm{H}, \mathrm{H}-1^{\prime}\right), 8.00(\mathrm{~s}$, $1 \mathrm{H}, \mathrm{H}-6), 8.50$ (br s, $1 \mathrm{H}, \mathrm{NH}$ ).

${ }^{13} \mathrm{C}$ NMR (101 MHz, $\left.\mathrm{CDCl}_{3}\right): \delta=-5.3,-5.2,-4.6,-4.4,18.1,18.6$, 25.8, 26.1, 42.0, 59.0, 61.6, 62.9, 68.9, 70.2, 70.3, 70.5, 72.2, 72.5, $77.5,85.7,88.2,89.7,99.3,142.7,148.9,161.3$.

ESI-MS: $m / z=665.5[\mathrm{M}+\mathrm{Na}]^{+}$.

\section{Compounds 3a and 3b; General Procedure}

To a solution of 2 (1.0 equiv) in $\mathrm{CH}_{2} \mathrm{Cl}_{2}$ at $0{ }^{\circ} \mathrm{C}$ was added DIPEA (2a: 1.8 equiv, $\mathbf{2 b}: 1.5$ equiv) and stirred for $\mathbf{2 a}$ : $30 \mathrm{~min}, \mathbf{2 b}: 10 \mathrm{~min}$, then $\mathrm{MsCl}$ (1.2 equiv) was added slowly and the mixture stirred; for 2a: $40 \mathrm{~min}, \mathbf{2 b}: 20 \mathrm{~min}$ at $0{ }^{\circ} \mathrm{C}$ (in the case of $\mathbf{2 b}$, the mixture was evaporated and the crude product was used directly without purification). For $\mathbf{2 a}$, the mixture was combined with sat. aq $\mathrm{NaHCO}_{3}(10$ $\mathrm{mL})$ and extracted with $\mathrm{Et}_{2} \mathrm{O}(3 \times 15 \mathrm{~mL})$. The combined organic layers were washed with brine $(15 \mathrm{~mL})$, dried $\left(\mathrm{MgSO}_{4}\right)$, and concentrated in vacuo. The residue was purified by flash chromatography [silica gel (EtOAc-PE, 1:2); $R_{f}=0.8$ (EtOAc-PE, 3:1)]. To a solution of the respective mesylate (1.0 equiv) in DMF was added $\mathrm{NaN}_{3}$ (2a: 6.5 equiv, 2b: 5.0 equiv). The mixture was warmed to $35^{\circ} \mathrm{C}$ for $20 \mathrm{~h}$, then combined with sat. aq $\mathrm{NaHCO}_{3}(5 \mathrm{~mL})$ and extracted with EtOAc $(3 \times 5 \mathrm{~mL})$. The combined organic layers were dried $\left(\mathrm{MgSO}_{4}\right)$, and concentrated in vacuo. The residue was purified by flash chromatography.

\section{3',5'-Bis-O-(tert-butyldimethylsilyl)-5-(5-methanesulfonate-} pent-1-ynyl)-2'-deoxyuridine

Prepared from 2a $(0.32 \mathrm{~g}, 0.59 \mathrm{mmol})$, DIPEA $(182 \mu \mathrm{L}, 1.07$ $\mathrm{mmol})$, and $\mathrm{MsCl}(55 \mu \mathrm{L}, 0.71 \mathrm{mmol})$ in $\mathrm{CH}_{2} \mathrm{Cl}_{2}(5 \mathrm{~mL})$; yield: 270 $\operatorname{mg}(74 \%)$.

${ }^{1} \mathrm{H}$ NMR $\left(600 \mathrm{MHz}, \mathrm{CDCl}_{3}\right): \delta=0.07\left(\mathrm{~s}, 3 \mathrm{H}, \mathrm{CH}_{3} \mathrm{Si}\right), 0.08(\mathrm{~s}, 3 \mathrm{H}$, $\mathrm{CH}_{3} \mathrm{Si}$ ), 0.13 (s, $\left.3 \mathrm{H}, \mathrm{CH}_{3} \mathrm{Si}\right), 0.14$ (s, $\left.3 \mathrm{H}, \mathrm{CH}_{3} \mathrm{Si}\right), 0.89$ (s, $9 \mathrm{H}, t$ $\left.\mathrm{C}_{4} \mathrm{H}_{9} \mathrm{Si}\right), 0.93\left(\mathrm{~s}, 9 \mathrm{H}, t-\mathrm{C}_{4} \mathrm{H}_{9} \mathrm{Si}\right), 1.97-2.05\left(\mathrm{~m}, 3 \mathrm{H}, \mathrm{H}-2^{\prime} \mathrm{a}\right.$, $\mathrm{CH}_{2} \mathrm{CH}_{2} \mathrm{CH}_{2} \mathrm{OMs}$ ), $2.31\left(\mathrm{ddd},{ }^{2} J_{2^{\prime} \mathrm{b}, 2^{\prime} \mathrm{a}}=13.1 \mathrm{~Hz},{ }^{3} J_{2^{\prime} \mathrm{b}, 1^{\prime}}=6.0 \mathrm{~Hz}\right.$, $\left.{ }^{3} J_{2^{\prime} \mathrm{b}, 3^{\prime}}=2.7 \mathrm{~Hz}, 1 \mathrm{H}, \mathrm{H}-2^{\prime} \mathrm{b}\right), 2.55\left(\mathrm{dd},{ }^{3} J=6.8 \mathrm{~Hz},{ }^{3} J=6.8 \mathrm{~Hz}, 2 \mathrm{H}\right.$,
$\mathrm{CH}_{2} \mathrm{CH}_{2} \mathrm{CH}_{2} \mathrm{OMs}$ ), 3.07 (s, $3 \mathrm{H}, \mathrm{OSO}_{2} \mathrm{CH}_{3}$ ), 3.77 (dd, ${ }^{2} J_{5^{\prime} \mathrm{b}, 5^{\prime} \mathrm{a}}=11.5$ $\left.\mathrm{Hz},{ }^{3} J_{5^{\prime} \mathrm{b}, 4^{\prime}}=2.1 \mathrm{~Hz}, 1 \mathrm{H}, \mathrm{H}-5^{\prime} \mathrm{b}\right), 3.89\left(\mathrm{dd},{ }^{2} J_{5^{\prime} \mathrm{a}, 5^{\prime} \mathrm{b}}=11.5 \mathrm{~Hz}\right.$, $\left.{ }^{3} J_{5^{\prime} \mathrm{a} 4^{\prime}}=2.4 \mathrm{~Hz}, 1 \mathrm{H}, \mathrm{H}-5^{\prime} \mathrm{a}\right), 3.96-3.98$ (m, $\left.1 \mathrm{H}, \mathrm{H}-4^{\prime}\right), 4.37-4.41$ $\left(\mathrm{m}, 3 \mathrm{H}, \mathrm{H}-3^{\prime}, \mathrm{CH}_{2} \mathrm{CH}_{2} \mathrm{CH}_{2} \mathrm{OMs}\right), 6.27$ (dd, ${ }^{3} J_{1^{\prime}, 2^{\prime} \mathrm{a}}=7.3 \mathrm{~Hz}$, $\left.{ }^{3} J_{1^{\prime}, 2^{\prime} \mathrm{b}}=6.0 \mathrm{~Hz}, 1 \mathrm{H}, \mathrm{H}-1^{\prime}\right), 7.94$ (s, $\left.1 \mathrm{H}, \mathrm{H}-6\right), 8.05$ (br s, $1 \mathrm{H}, \mathrm{NH}$ ). ${ }^{13} \mathrm{C} \mathrm{NMR}\left(151 \mathrm{MHz}, \mathrm{CDCl}_{3}\right): \delta=-4.5,-4.4,-3.8,-3.6,16.9,19.0$, 19.5, 26.7, 27.0, 28.8, 38.2, 42.9, 49.3, 64.0, 69.5, 73.3, 86.7, 89.4, 93.4, 101.1, 143.0, 150.0, 162.6.

ESI-MS: $m / z=639.4[\mathrm{M}+\mathrm{Na}]^{+}$.

Anal. Calcd for $\mathrm{C}_{27} \mathrm{H}_{48} \mathrm{~N}_{2} \mathrm{O}_{8} \mathrm{SSi}_{2}$ : C, 52.57; H, 7.84; N, 4.54. Found: C, $52.62 ; \mathrm{H}, 7.77 ; \mathrm{N}, 4.50$.

\section{3',5'-Bis- $O$-(tert-butyldimethylsilyl)-5-(5-azidopent-1-ynyl)-2'-} deoxyuridine (3a)

Prepared from mesylate derived from $\mathbf{2 a}(70 \mathrm{mg}, 0.11 \mathrm{mmol})$, and $\mathrm{NaN}_{3}$ (46 mg, $0.71 \mathrm{mmol}$ ) in DMF (2 mL). Purification: silica gel (EtOAc-PE, 1:3 to $1: 1$ ); $R_{f}=0.8$ (EtOAc-PE, 1:1); yield: $61 \mathrm{mg}$ $(95 \%)$.

${ }^{1} \mathrm{H}$ NMR $\left(600 \mathrm{MHz}, \mathrm{CDCl}_{3}\right): \delta=0.09\left(\mathrm{~s}, 3 \mathrm{H}, \mathrm{CH}_{3} \mathrm{Si}\right), 0.1(\mathrm{~s}, 3 \mathrm{H}$, $\left.\mathrm{CH}_{3} \mathrm{Si}\right), 0.15$ (s, $\left.3 \mathrm{H}, \mathrm{CH}_{3} \mathrm{Si}\right), 0.16\left(\mathrm{~s}, 3 \mathrm{H}, \mathrm{CH}_{3} \mathrm{Si}\right), 0.91(\mathrm{~s}, 9 \mathrm{H}, t-$ $\mathrm{C}_{4} \mathrm{H}_{9} \mathrm{Si}$ ), 0.95 (s, $9 \mathrm{H}, t-\mathrm{C}_{4} \mathrm{H}_{9} \mathrm{Si}$ ), 1.85 (dddd, ${ }^{3} J=6.8,6.8,6.8,6.8$ $\mathrm{Hz}, 2 \mathrm{H}, \mathrm{CH}_{2} \mathrm{CH}_{2} \mathrm{CH}_{2} \mathrm{~N}_{3}$ ), 2.03 (ddd, ${ }^{2} J_{2^{\prime} \mathrm{a}, 2^{\prime} \mathrm{b}}=13.3 \mathrm{~Hz},{ }^{3} J_{2^{\prime} \mathrm{a}, 1^{\prime}}=7.7$ $\left.\mathrm{Hz},{ }^{3} J_{2^{\prime} \mathrm{a}, 3^{\prime}}=6.3 \mathrm{~Hz}, 1 \mathrm{H}, \mathrm{H}-2^{\prime} \mathrm{a}\right), 2.31$ (ddd, ${ }^{2} J_{2^{\prime} \mathrm{b}, 2^{\prime} \mathrm{a}}=13.3 \mathrm{~Hz}$, $\left.{ }^{3} J_{2^{\prime} \mathrm{b}, 1^{\prime}}=5.9 \mathrm{~Hz},{ }^{3} J_{2^{\prime} \mathrm{b}, 3^{\prime}}=2.7 \mathrm{~Hz}, 1 \mathrm{H}, \mathrm{H}-2^{\prime} \mathrm{b}\right), 2.51\left(\mathrm{t},{ }^{3} J=6.8 \mathrm{~Hz}, 2\right.$ $\left.\mathrm{H}, \mathrm{CH}_{2} \mathrm{CH}_{2} \mathrm{CH}_{2} \mathrm{~N}_{3}\right), 3.45\left(\mathrm{t},{ }^{3} \mathrm{~J}=6.8 \mathrm{~Hz}, 2 \mathrm{H}, \mathrm{CH}_{2} \mathrm{CH}_{2} \mathrm{CH}_{2} \mathrm{~N}_{3}\right), 3.78$ $\left(\mathrm{dd},{ }^{2} J_{5^{\prime} \mathrm{b}, 5^{\prime} \mathrm{a}}=11.5 \mathrm{~Hz},{ }^{3} J_{5^{\prime} \mathrm{b}, 4^{\prime}}=2.2 \mathrm{~Hz}, 1 \mathrm{H}, \mathrm{H}-5^{\prime} \mathrm{b}\right), 3.91$ (dd, $\left.{ }^{2} J_{5^{\prime} \mathrm{a}, 5^{\prime} \mathrm{b}}=11.5 \mathrm{~Hz},{ }^{3} J_{5^{\prime} \mathrm{a}, 4^{\prime}}=2.3 \mathrm{~Hz}, 1 \mathrm{H}, \mathrm{H}-5^{\prime} \mathrm{a}\right), 3.98$ (ddd, $\left.{ }^{3} J_{4^{\prime}, 5^{\prime} \mathrm{b}}=2.2 \mathrm{~Hz},{ }^{3} J_{4^{\prime}, 5^{\prime} \mathrm{a}}=2.3 \mathrm{~Hz},{ }^{3} J_{4^{\prime}, 3^{\prime}}=2.2 \mathrm{~Hz}, 1 \mathrm{H}, \mathrm{H}-4^{\prime}\right), 4.40-$ $4.43\left(\mathrm{~m}, 1 \mathrm{H}, \mathrm{H}-3^{\prime}\right), 6.3\left(\mathrm{dd},{ }^{3} J_{1^{\prime}, 2^{\prime} \mathrm{a}}=7.7 \mathrm{~Hz},{ }^{3} J_{1^{\prime}, 2^{\prime} \mathrm{b}}=5.9 \mathrm{~Hz}, 1 \mathrm{H}, \mathrm{H}-\right.$ 1'), 7.93 (s, $1 \mathrm{H}, \mathrm{H}-6$ ), 8.27 (br s, $1 \mathrm{H}, \mathrm{NH}$ ).

${ }^{13} \mathrm{C} \mathrm{NMR}\left(151 \mathrm{MHz}, \mathrm{CDCl}_{3}\right): \delta=-4.5,-4.4,-3.8,-3.6,18.0,19.0$, 19.5, 26.8, 27.0, 28.7, 43.0, 51.3, 64.0, 73.4, 73.5, 86.7, 89.4, 94.1, 101.4, 142.9, 150.0, 162.5.

ESI-MS: $m / z=586.6[\mathrm{M}+\mathrm{Na}]^{+}$.

3',5'-Bis- $O$-(tert-butyldimethylsilyl)-5-[12-azido-(4,7,10-trioxadodec-1-ynyl)]-2'-deoxyuridine (3b)

Prepared from $2 \mathbf{b}(0.1 \mathrm{~g}, 0.16 \mathrm{mmol})$, DIPEA ( $40 \mu \mathrm{L}, 0.23 \mathrm{mmol})$, $\mathrm{MsCl}(38 \mu \mathrm{L}, 0.18 \mathrm{mmol})$ in $\mathrm{CH}_{2} \mathrm{Cl}_{2}(5 \mathrm{~mL})$ followed by the addition of $\mathrm{NaN}_{3}(50 \mathrm{mg}, 0.78 \mathrm{mmol})$ and DMF $(2 \mathrm{~mL})$. Purification: silica gel $\left(\mathrm{CH}_{2} \mathrm{Cl}_{2}-\mathrm{MeOH}, 20: 1\right) ; R_{f}=0.8\left(\mathrm{CH}_{2} \mathrm{Cl}_{2}-\mathrm{MeOH}, 20: 1\right)$; yield: $53 \mathrm{mg}$ (50\% over two steps).

${ }^{1} \mathrm{H}$ NMR $\left(600 \mathrm{MHz}, \mathrm{CDCl}_{3}\right): \delta=0.08\left(\mathrm{~s}, 3 \mathrm{H}, \mathrm{CH}_{3} \mathrm{Si}\right), 0.09$ (s, $3 \mathrm{H}$, $\left.\mathrm{CH}_{3} \mathrm{Si}\right), 0.14$ (s, $\left.3 \mathrm{H}, \mathrm{CH}_{3} \mathrm{Si}\right), 0.15$ (s, $\left.3 \mathrm{H}, \mathrm{CH}_{3} \mathrm{Si}\right), 0.90$ (s, $9 \mathrm{H}, t$ $\left.\mathrm{C}_{4} \mathrm{H}_{9} \mathrm{Si}\right), 0.94\left(\mathrm{~s}, 9 \mathrm{H}, t-\mathrm{C}_{4} \mathrm{H}_{9} \mathrm{Si}\right), 2.03\left(\mathrm{ddd},{ }^{2} J_{2^{\prime} \mathrm{a}, 2^{\prime} \mathrm{b}}=13.2 \mathrm{~Hz}\right.$, ${ }^{3} J_{2^{\prime} \mathrm{a}, 1^{\prime}}=7.6 \mathrm{~Hz},{ }^{3} J_{2^{\prime} \mathrm{a}, 3^{\prime}}=6.0 \mathrm{~Hz}, 1 \mathrm{H}, \mathrm{H}-2^{\prime} \mathrm{a}$ ), 2.33 (ddd, $\left.{ }^{2} J_{2^{\prime} \mathrm{b}, 2^{\prime} \mathrm{a}}=13.2 \mathrm{~Hz},{ }^{3} J_{2^{\prime} \mathrm{b}, 1^{\prime}}=5.9 \mathrm{~Hz},{ }^{3} J_{2^{\prime} \mathrm{b}, 3^{\prime}}=2.6 \mathrm{~Hz}, 1 \mathrm{H}, \mathrm{H}-2^{\prime} \mathrm{b}\right), 3.40$ $\left(\mathrm{t},{ }^{3} \mathrm{~J}=5.1 \mathrm{~Hz}, 2 \mathrm{H}, \mathrm{OCH}_{2} \mathrm{CH}_{2} \mathrm{~N}_{3}\right), 3.67-3.71\left(\mathrm{~m}, 8 \mathrm{H}, \mathrm{OCH}_{2} \mathrm{CH}_{2} \mathrm{O}\right)$, $3.72-3.75\left(\mathrm{~m}, 2 \mathrm{H}, \mathrm{OCH}_{2} \mathrm{CH}_{2} \mathrm{~N}_{3}\right), 3.77\left(\mathrm{dd},{ }^{2} J_{5^{\prime} \mathrm{b}, 5^{\prime} \mathrm{a}}=11.4 \mathrm{~Hz}\right.$, $\left.{ }^{3} J_{5^{\prime} \mathrm{b}, 4^{\prime}}=2 \mathrm{~Hz}, 1 \mathrm{H}, \mathrm{H}-5^{\prime} \mathrm{b}\right), 3.90\left(\mathrm{dd},{ }^{2} J_{5^{\prime} \mathrm{a}, 5^{\prime} \mathrm{b}}=11.4 \mathrm{~Hz},{ }^{3} J_{5^{\prime} \mathrm{a}, 4^{\prime}}=2.4\right.$ $\left.\mathrm{Hz}, 1 \mathrm{H}, \mathrm{H}-5^{\prime} \mathrm{a}\right), 3.97-4.00$ (m, $\left.1 \mathrm{H}, \mathrm{H}-4^{\prime}\right), 4.39$ (s, $\left.2 \mathrm{H}, \mathrm{CH}_{2} \mathrm{O}\right)$, $4.40-4.43\left(\mathrm{~m}, 1 \mathrm{H}, \mathrm{H}-3^{\prime}\right), 6.29\left(\mathrm{dd},{ }^{3} J_{1^{\prime}, 2^{\prime} \mathrm{a}}=7.6 \mathrm{~Hz},{ }^{3} J_{1^{\prime}, 2^{\prime} \mathrm{b}}=5.9 \mathrm{~Hz}\right.$, $1 \mathrm{H}, \mathrm{H}^{-1}{ }^{\prime}$ ), 8.02 (s, $\left.1 \mathrm{H}, \mathrm{H}-6\right), 8.40$ (br s, $1 \mathrm{H}, \mathrm{NH}$ ).

${ }^{13} \mathrm{C} \mathrm{NMR}\left(151 \mathrm{MHz}, \mathrm{CDCl}_{3}\right): \delta=-4.5,-4.4,-3.8,-3.6,19.0,19.4$, 26.7, 27.0, 43.0, 51.7, 60.0, 64.0, 70.2, 71.0, 71.5, 71.6, 71.7, 73.4, 78.4, 86.9, 89.4, 90.6, 100.5, 144.1, 150.0, 162.2.

ESI-MS: $m / z=690.3[\mathrm{M}+\mathrm{Na}]^{+}$.

\section{Compounds 4a and 4b; General Procedure}

To a solution of $\mathbf{3}$ (1.0 equiv) in THF, was added TBAF ( $1 \mathrm{M}$ solution in THF; 2.2 equiv) at $0{ }^{\circ} \mathrm{C}$. The mixture was allowed to warm to r.t. and stirred; for $3 \mathbf{a}: 16 \mathrm{~h}, \mathbf{3 b}: 20 \mathrm{~h}$, and evaporated in vacuo to give the crude unprotected sugar, which was purified by flash chromatography. This product (1.0 equiv) and proton sponge $[1,8-$ 
bis(dimethylaminonaphthalene)] (1.5 equiv) were dried overnight protected from light in vacuo, dissolved in trimethyl phosphate, and cooled to $0{ }^{\circ} \mathrm{C}$. Freshly distilled $\mathrm{POCl}_{3}$ (4a: 1.3 equiv, 4b: 2.2 equiv) was added to the mixture and stirred; for $4 \mathrm{a}: 3.5 \mathrm{~h}, 4 \mathbf{b}: 4.5 \mathrm{~h}$. A $0.5 \mathrm{M}$ soln of $\left(\mathrm{Bu}_{3} \mathrm{NH}\right)_{2} \mathrm{H}_{2} \mathrm{P}_{2} \mathrm{O}_{7}$ in anhyd DMF (4a: 5 equiv, $4 \mathbf{b}$ : 10 equiv) and $\mathrm{Bu}_{3} \mathrm{~N}$ (4a: 10 equiv, $\mathbf{4 b}$ : 20 equiv) were added simultaneously to the mixture. After $5 \mathrm{~min}, 1 \mathrm{M}$ aq triethylammonium bicarbonate (TEAB buffer, $\mathrm{pH} 7.5$ ) was added and the aqueous layer was washed with EtOAc $(2 \times 10 \mathrm{~mL})$. The aqueous layer was lyophilized and the resulting residue purified by ion-exchange chromatography [DEAE-Sephadex A-25, linear gradient of TEAB buffer ( $0.1 \mathrm{M}$ to $1 \mathrm{M}, 1000 \mathrm{~mL}$ ), flow $2 \mathrm{~mL} / \mathrm{min}$ ] and further purified by RP-MPLC (RP-18, 40-63 $\mu \mathrm{m})$ using a gradient of $5 \%(200 \mathrm{~mL})$, $20 \%$ (200 mL) and 40\% (200 mL) MeCN in $50 \mathrm{mM}$ aq triethylammonium acetate (TEAA buffer, $\mathrm{pH}$ 7.0). The triphosphates $\mathbf{4 a}$ and $4 \mathbf{b}$ were eluted with $20 \% \mathrm{MeCN}$ in $50 \mathrm{mM}$ aq TEAA buffer.

\section{5-(5-Azidopent-1-ynyl)-2'-deoxyuridine}

Prepared from 3a (58 mg, $0.10 \mathrm{mmol})$, TBAF soln $(226 \mu \mathrm{L}, 0.23$ $\mathrm{mmol})$ in THF $(2 \mathrm{~mL})$. Purification: silica gel $\left(\mathrm{CH}_{2} \mathrm{Cl}_{2}-\mathrm{MeOH}\right.$, $20: 1) ; R_{f}=0.6\left(\mathrm{CH}_{2} \mathrm{Cl}_{2}-\mathrm{MeOH}, 20: 1\right)$; yield: $32 \mathrm{mg}$ (93\%).

${ }^{1} \mathrm{H}$ NMR (400 MHz, MeOD): $\delta=1.75$ (dddd, ${ }^{3} J=6.8,6.8,6.8,6.8$ $\mathrm{Hz}, 2 \mathrm{H}, \mathrm{CH}_{2} \mathrm{CH}_{2} \mathrm{CH}_{2} \mathrm{~N}_{3}$ ), 2.10-2.26 (m, $\left.2 \mathrm{H}, \mathrm{H}-2^{\prime} \mathrm{a}, \mathrm{H}-2^{\prime} \mathrm{b}\right), 2.43$ (t, $\left.{ }^{3} \mathrm{~J}=6.8 \mathrm{~Hz}, 2 \mathrm{H}, \mathrm{CH}_{2} \mathrm{CH}_{2} \mathrm{CH}_{2} \mathrm{~N}_{3}\right), 3.40\left(\mathrm{t},{ }^{3} \mathrm{~J}=6.8 \mathrm{~Hz}, 2 \mathrm{H}\right.$, $\left.\mathrm{CH}_{2} \mathrm{CH}_{2} \mathrm{CH}_{2} \mathrm{~N}_{3}\right), 3.67\left(\mathrm{dd},{ }^{2} J_{5^{\prime} \mathrm{b}, 5^{\prime} \mathrm{a}}=12.0 \mathrm{~Hz},{ }^{3} J_{5^{\prime} \mathrm{b} 4^{\prime}}=3.4 \mathrm{~Hz}, 1 \mathrm{H}\right.$, $\left.\mathrm{H}-5^{\prime} \mathrm{b}\right), 3.75\left(\mathrm{dd},{ }^{2} J_{5^{\prime} \mathrm{a}, 5^{\prime} \mathrm{b}}=12.0 \mathrm{~Hz},{ }^{3} J_{5^{\prime} \mathrm{a}, 4^{\prime}}=3.0 \mathrm{~Hz}, 1 \mathrm{H}, \mathrm{H}-5^{\prime} \mathrm{a}\right)$, 3.84-3.88 (m, $\left.1 \mathrm{H}, \mathrm{H}-4^{\prime}\right), 4.31-4.36\left(\mathrm{~m}, 1 \mathrm{H}, \mathrm{H}-3^{\prime}\right), 6.18(\mathrm{t}$, $\left.{ }^{3} J_{1^{\prime}, 2^{\prime} \mathrm{a}}={ }^{3} J_{1^{\prime}, 2^{\prime} \mathrm{b}}=6.6 \mathrm{~Hz}, 1 \mathrm{H}, \mathrm{H}-1^{\prime}\right), 8.19$ (s, $\left.1 \mathrm{H}, \mathrm{H}-6\right)$.

${ }^{13} \mathrm{C}$ NMR (101 MHz, $\left.\mathrm{CDCl}_{3}\right): \delta=17.3,28.8,41.6,51.3,62.7,72.2$, 73.7, 87.1, 89.4, 93.8, 101.3, 145.1, 151.9, 165.5.

ESI-MS: $m / z=357.9[\mathrm{M}+\mathrm{Na}]^{+}$.

\section{5-(5-Azidopent-1-ynyl)-2' -deoxyuridine-5' -triphosphate (4a)}

Prepared from 5-(5-azidopent-1-ynyl)-2'-deoxyuridine (29 mg, 86 $\mu \mathrm{mol})$, proton sponge $(28 \mathrm{mg}, 0.13 \mathrm{mmol}), \mathrm{POCl}_{3}(10.5 \mu \mathrm{L}, 0.11$ mmol), $\left(\mathrm{Bu}_{3} \mathrm{NH}\right)_{2} \mathrm{H}_{2} \mathrm{P}_{2} \mathrm{O}_{7}$ solution $(0.86 \mathrm{~mL}, 0.43 \mathrm{mmol}), \mathrm{Bu}_{3} \mathrm{~N}$ $(229 \mu \mathrm{L}, 0.86 \mathrm{mmol})$, and trimethyl phosphate $(1 \mathrm{~mL})$; yield: 25.7 $\mathrm{mg}(30 \%)$.

${ }^{1} \mathrm{H}$ NMR (400 MHz, MeOD): $\delta=1.20-1.35\left[\mathrm{~m}, 36 \mathrm{H},\left(\mathrm{HNEt}_{3}\right)^{+}{ }_{4}\right]$, 1.8-1.93 (m, $\left.2 \mathrm{H}, \mathrm{CH}_{2} \mathrm{CH}_{2} \mathrm{CH}_{2} \mathrm{~N}_{3}\right), 2.30-2.40\left(\mathrm{~m}, 2 \mathrm{H}, \mathrm{H}-2^{\prime} \mathrm{b}, \mathrm{H}-\right.$ 2'a), 2.47-2.55 (m, $2 \mathrm{H}, \mathrm{CH}_{2} \mathrm{CH}_{2} \mathrm{CH}_{2} \mathrm{~N}_{3}$ ), 3.13-3.25 [m, H-5'a, H$\left.5^{\prime} \mathrm{b},\left(\mathrm{HNEt}_{3}\right)_{4}^{+}\right], 3.25-3.46\left(\mathrm{~m}, 2 \mathrm{H}, \mathrm{CH}_{2} \mathrm{CH}_{2} \mathrm{CH}_{2} \mathrm{~N}_{3}\right), 4.1-4.2(\mathrm{~m}, 1$ H, H-3'), 4.56-4.62 (m, $\left.1 \mathrm{H}, \mathrm{H}-4^{\prime}\right), 6.26$ (m, $\left.1 \mathrm{H}, \mathrm{H}-1^{\prime}\right), 8.0$ (s, $1 \mathrm{H}$, H-6).

${ }^{31} \mathrm{P}$ NMR (162 MHz, MeOD): $\delta=-22.5\left(\mathrm{~m}, 1 \mathrm{P}, \mathrm{P}_{\beta}\right),-10.6(\mathrm{~d}$, $\left.{ }^{2} J_{\alpha, \beta}=20.2 \mathrm{~Hz}, 1 \mathrm{P}, \mathrm{P}_{\alpha}\right),-9.3\left(\mathrm{~d},{ }^{2} J_{\gamma, \beta}=20.2 \mathrm{~Hz}, 1 \mathrm{P}, \mathrm{P}_{\gamma}\right)$.

ESI-MS: $m / z=575.0[\mathrm{M}-\mathrm{H}]^{-}$.

\section{5-[12-Azido-(4,7,10-trioxadodec-1-ynyl)]-2'-deoxyuridine}

Prepared from 3b $(43 \mathrm{mg}, 64 \mu \mathrm{mol})$, TBAF soln $(142 \mu \mathrm{L}, 0.14$ mmol) in THF $(2 \mathrm{~mL})$. Purification: silica gel $\left(\mathrm{CH}_{2} \mathrm{Cl}_{2}-\mathrm{MeOH}\right.$, 20:1); $R_{f}=0.5\left(\mathrm{CH}_{2} \mathrm{Cl}_{2}-\mathrm{MeOH}, 10: 1\right)$; yield: $26.5 \mathrm{mg}$ (94\%).

${ }^{1} \mathrm{H}$ NMR (600 MHz, MeOD): $\delta=2.23\left(\mathrm{ddd},{ }^{2} J_{2^{\prime}, 2^{\prime} \mathrm{b}}=13.5 \mathrm{~Hz}\right.$, ${ }^{3} J_{2^{\prime} \mathrm{a}, 1^{\prime}}=6.3 \mathrm{~Hz},{ }^{3} J_{2^{\prime} \mathrm{a}, 3^{\prime}}=6.5 \mathrm{~Hz}, 1 \mathrm{H}, \quad \mathrm{H}-2^{\prime} \mathrm{a}$ ), 2.32 (ddd, $\left.{ }^{2} J_{2^{\prime} \mathrm{b}, 2^{\prime} \mathrm{a}}=13.5 \mathrm{~Hz},{ }^{3} J_{2^{\prime} \mathrm{b}, 1^{\prime}}=6.3 \mathrm{~Hz},{ }^{3} J_{2^{\prime} \mathrm{b}, 3^{\prime}}=3.7 \mathrm{~Hz}, 1 \mathrm{H}, \mathrm{H}-2^{\prime} \mathrm{b}\right), 3.38$ $\left(\mathrm{t},{ }^{3} \mathrm{~J}=4.9 \mathrm{~Hz}, 2 \mathrm{H}, \mathrm{OCH}_{2} \mathrm{CH}_{2} \mathrm{~N}_{3}\right), 3.65-3.70\left(\mathrm{~m}, 8 \mathrm{H}, \mathrm{OCH}_{2} \mathrm{CH}_{2} \mathrm{O}\right)$, 3.72-3.76 (m, $\left.3 \mathrm{H}, \mathrm{H}-5^{\prime} \mathrm{b}, \mathrm{OCH}_{2} \mathrm{CH}_{2} \mathrm{~N}_{3}\right), 3.90\left(\mathrm{dd},{ }^{2} J_{5^{\prime} \mathrm{a}, 5^{\prime} \mathrm{b}}=12.0\right.$ $\left.\mathrm{Hz},{ }^{3} J_{5^{\prime} \mathrm{a}, 4^{\prime}}=3.0 \mathrm{~Hz}, 1 \mathrm{H}, \mathrm{H}-5^{\prime} \mathrm{a}\right), 3.92-4.00\left(\mathrm{~m}, 1 \mathrm{H}, \mathrm{H}-4^{\prime}\right), 4.38$ (s, $\left.2 \mathrm{H}, \mathrm{CH}_{2} \mathrm{O}\right), 4.39-4.42\left(\mathrm{~m}, 1 \mathrm{H}, \mathrm{H}-3^{\prime}\right), 6.24\left(\mathrm{t},{ }^{3} J_{1^{\prime}, 2^{\prime} \mathrm{a}}={ }^{3} J_{1^{\prime}, 2^{\prime} \mathrm{b}}=6.3\right.$ $\mathrm{Hz}, 1 \mathrm{H}, \mathrm{H}-1^{\prime}$ ), 8.35 (s, $1 \mathrm{H}, \mathrm{H}-6$ ).

${ }^{13} \mathrm{C}$ NMR $\left(151 \mathrm{MHz}, \mathrm{CDCl}_{3}\right): \delta=41.8,51.8,59.7,62.5,70.2,71.1$, 71.4, 71.5, 71.6, 71.9, 78.8, 87.1, 89.2, 90.2, 100.0, 145.7, 151.2, 164.3.

ESI-MS: $m / z=463.2[\mathrm{M}+\mathrm{Na}]^{+}$.
5-[12-Azido-(4,7,10-trioxa-1-dodecynyl)]-2'-deoxyuridine-5'triphosphate (4b)

Prepared from 5-[12-azido-(4,7,10-trioxadodec-1-ynyl)]-2'-deoxyuridine $(26.5 \mathrm{mg}, 60 \mu \mathrm{mol})$, proton sponge $(19.4 \mathrm{mg}, 90 \mu \mathrm{mol})$, $\mathrm{POCl}_{3}(17 \mu \mathrm{L}, 0.19 \mathrm{mmol}),\left(\mathrm{Bu}_{3} \mathrm{NH}\right)_{2} \mathrm{H}_{2} \mathrm{P}_{2} \mathrm{O}_{7}$ solution $(1.2 \mathrm{~mL}, 0.6$ $\mathrm{mmol}), \mathrm{Bu}_{3} \mathrm{~N}(0.32 \mathrm{~mL}, 1.2 \mathrm{mmol})$, and trimethyl phosphate (1 $\mathrm{mL})$; yield: $15.4 \mathrm{mg}(24 \%)$.

${ }^{1} \mathrm{H}$ NMR $(600 \mathrm{MHz}, \mathrm{MeOD}): \delta=1.27\left[\mathrm{t},{ }^{3} J=7.0 \mathrm{~Hz},\left(\mathrm{HNEt}_{3}\right)^{+}{ }_{4}\right]$, 2.27 (m, 2 H, H-2'b, H-2'a), 3.07-3.12 [m, $\left.\left(\mathrm{HNEt}_{3}\right)^{+}{ }_{4}\right], 3.37$ (t, $\left.{ }^{3} J=4.9 \mathrm{~Hz}, 2 \mathrm{H}, \mathrm{OCH}_{2} \mathrm{CH}_{2} \mathrm{~N}_{3}\right), 3.64-3.69\left(\mathrm{~m}, 8 \mathrm{H}, \mathrm{OCH}_{2} \mathrm{CH}_{2} \mathrm{O}\right)$, 3.71-3.74 (m, $2 \mathrm{H}, \mathrm{OCH}_{2} \mathrm{CH}_{2} \mathrm{~N}_{3}$ ), 4.06-4.10 (m, $\left.1 \mathrm{H}, \mathrm{H}-4^{\prime}\right)$, 4.144.19 (m, $\left.1 \mathrm{H}, \mathrm{H}-5^{\prime} \mathrm{b}\right), 4.24-4.3$ (m, $\left.1 \mathrm{H}, \mathrm{H}-5^{\prime} \mathrm{a}\right), 4.40$ (s, $\left.2 \mathrm{H}, \mathrm{CH}_{2} \mathrm{O}\right)$, $4.58-4.61\left(\mathrm{~m}, 1 \mathrm{H}, \mathrm{H}-3^{\prime}\right), 6.22\left(\mathrm{t},{ }^{3} J_{1^{\prime}, 2^{\prime} \mathrm{a}}={ }^{3} J_{1^{\prime}, 2^{\prime} \mathrm{b}}=6.8 \mathrm{~Hz}, 1 \mathrm{H}, \mathrm{H}-\right.$ $\left.1^{\prime}\right), 8.08$ (s, $\left.1 \mathrm{H}, \mathrm{H}-6\right)$.

${ }^{31} \mathrm{P}$ NMR $(162 \mathrm{MHz}, \mathrm{MeOD}): \delta=-21.6\left(\mathrm{~m}, 1 \mathrm{P}, \mathrm{P}_{\beta}\right),-10.4(\mathrm{~d}$, $\left.{ }^{2} J_{\alpha, \beta}=21.6 \mathrm{~Hz}, 1 \mathrm{P}, \mathrm{P}_{\alpha}\right),-8.6\left(\mathrm{~d},{ }^{2} J_{\gamma, \beta}=20.8 \mathrm{~Hz}, 1 \mathrm{P}, \mathrm{P}_{\gamma}\right)$.

ESI-MS: $m / z=677.8[\mathrm{M}-\mathrm{H}]^{-}$.

\section{Primer Extension}

DNA primer strands were purchased from IBA, dNTPs were from Roche, $P$ wo DNA polymerase, $10 \times P$ wo reaction buffer $(100 \mathrm{mM}$ Tris $\cdot \mathrm{HCl}(\mathrm{pH} 8.8), 250 \mathrm{mM} \mathrm{KCl}, 20 \mathrm{mM} \mathrm{MgSO}{ }_{4}$ ) were from Peqlab. A typical primer extension reaction $(20 \mu \mathrm{L})$ contained $1 \times P$ wo reaction buffer, $150 \mathrm{nM}{ }^{32} \mathrm{P}$-labeled primer, $200 \mathrm{nM}$ template, $100 \mu \mathrm{M}$ each of $\mathbf{4 a}$ or $\mathbf{4 b}, 100 \mu \mathrm{M}$ each of dATP, dCTP, dGTP, and $0.12 \mathrm{U} / 20 \mu \mathrm{L} P$ wo DNA polymerase. First primer and template were annealed in $1 \times P$ wo reaction buffer by heating the probes to $95{ }^{\circ} \mathrm{C}$ and allowing to cool down to $20^{\circ} \mathrm{C}$. Afterwards the primer template complex, nucleotides, and $P$ wo DNA polymerase were incubated at $72{ }^{\circ} \mathrm{C}$ for $30 \mathrm{~min}$. The reactions were quenched by addition of $20 \mu \mathrm{L}$ PAGE gel loading buffer ( $80 \%$ formamide, 20 mM EDTA, $0.1 \%$ bromophenol blue, $0.1 \%$ xylene cyanole FF) and the product mixtures were analyzed by $12 \%$ denaturing polyacrylamide gel, and subjected to autoradiography.

\section{Staudinger Ligation on DNA 1}

The primer extension product was used for the Staudinger ligation. The modified DNA was prepared according to the procedure mentioned above. The concentrations of dNTPs and Pwo DNA polymerase were adjusted to $200 \mu \mathrm{M}$ and to $0.5 \mathrm{U} / 20 \mu \mathrm{L}$, respectively. After incubation at $72{ }^{\circ} \mathrm{C}$ for $60 \mathrm{~min}$, the $20 \mu \mathrm{L}$ reactions were quenched with $1 \mu \mathrm{L}$ of $210 \mathrm{mM}$ EDTA solution. The reaction product was purified using Sephadex G-25 spin columns. For the Staudinger ligation, $2.5 \mu \mathrm{L}$ of $1 \mathrm{M} \mathrm{NaHCO} / \mathrm{Na}_{2} \mathrm{CO}_{3}$ buffer $(\mathrm{pH}$ 9.0), $2.5 \mu \mathrm{L}$ of $\mathbf{5 a}$ or $\mathbf{5 b}(10 \mathrm{mM}$ in DMF) and $5 \mu \mathrm{L}$ of the primer extension product $(\sim 1 \mu \mathrm{M})$ were mixed and incubated either at $60{ }^{\circ} \mathrm{C}$ for $12 \mathrm{~h}$ or at various temperatures for $4 \mathrm{~h}$ in the case of temperature-dependence experiments. The reactions were stopped by adding $10 \mu \mathrm{L}$ of PAGE-gel-loading buffer and the product mixtures were analyzed by $12 \%$ denaturing polyacrylamide gel.

\section{PCR}

Typical PCR reactions $(20 \mu \mathrm{L})$ contained $1 \times P$ wo reaction buffer, $200 \mu \mathrm{M}$ each of $\mathbf{4 a}$ or $\mathbf{4 b}, 200 \mu \mathrm{M}$ each of dATP, dCTP, dGTP, 500 $\mathrm{nM}$ primer I, $500 \mathrm{nM}$ primer II, $1.2 \mathrm{pg} / \mu \mathrm{L}$ template (98 bp), and 0.02 $\mathrm{U} / \mu \mathrm{L} P$ wo DNA polymerase. A typical PCR cycling protocol began with an initial denaturation at $95^{\circ} \mathrm{C}$ for $60 \mathrm{~s}$ and was followed by 35 cycles of $95{ }^{\circ} \mathrm{C}, 30 \mathrm{~s} ; 55^{\circ} \mathrm{C}, 35 \mathrm{~s} ; 72{ }^{\circ} \mathrm{C}, 40 \mathrm{~s}$. The reactions were quenched by addition of $4 \mu \mathrm{L}$ agarose-gel-loading buffer $(10 \mathrm{mM}$ Tris $\cdot \mathrm{HCl}, 60 \mathrm{mM}$ EDTA, 30\% glycerol, $0.1 \%$ bromophenol blue, $0.1 \%$ xylene cyanole $\mathrm{FF}$ ) and the product mixtures were analyzed by agarose gel electrophoresis.

The PCR reaction using the $1.9 \mathrm{kB}$ plasmid as template was done according to the procedure mentioned above. The concentrations of plasmid DNA and Pwo DNA polymerase were adjusted to $0.4 \mathrm{ng} /$ $\mu \mathrm{L}$ and $0.04 \mathrm{U} / \mu \mathrm{L}$, respectively. The PCR cycling protocol was de- 
natured at $95^{\circ} \mathrm{C}$ for $120 \mathrm{~s}$, followed by 35 cycles of $95^{\circ} \mathrm{C}, 60 \mathrm{~s}$; $63{ }^{\circ} \mathrm{C}, 60 \mathrm{~s}$; and $72{ }^{\circ} \mathrm{C}, 240 \mathrm{~s}$. The reactions were quenched by the addition of $4 \mu \mathrm{L}$ agarose-gel-loading buffer and the product mixtures were analyzed by agarose gel electrophoresis.

\section{Acknowledgment}

The assistance of Dr. Karl-Heinz Jung in manuscript preparation is kindly acknowledged.

\section{References}

(1) (a) Niemeyer, C. M. Methods in Molecular Biology, Vol. 283; Humana Press: Totowa, 2004. (b) Kool, E. T. In Comprehensive Natural Products Chemistry, Vol. 7; Barton, D. H. R.; Nakanishi, K.; Meth-Cohn, O., Eds.; Pergamon Press: Oxford, 2002.

(2) (a) Breinbauer, R.; Köhn, M. ChemBioChem 2003, 4, 1147. (b) Köhn, M.; Breinbauer, R. Angew. Chem. Int. Ed. 2004, 43, 3106. (c) Bräse, S.; Gil, C.; Knepper, K.; Zimmermann, V. Angew. Chem. Int. Ed. 2005, 44, 5188.

(3) Huisgen, R. Angew. Chem., Int. Ed. Engl. 1963, 2, 565.

(4) (a) Rostovtsev, V. V.; Green, L. G.; Fokin, V. V.; Sharpless, K. B. Angew. Chem. Int. Ed. 2002, 41, 2596. (b) Tornoe, C. W.; Christensen, C.; Meldal, M. J. Org. Chem. 2002, 67, 3057.

(5) (a) Wang, Q.; Chan, T. R.; Hilgraf, R.; Fokin, V. V.; Sharpless, K. B.; Finn, M. G. J. Am. Chem. Soc. 2003, 125, 3192. (b) Speers, A. E.; Adam, G. C.; Cravatt, B. F. J. Am. Chem. Soc. 2003, 125, 4686. (c) Link, A. J.; Tirrell, D. A. J. Am. Chem. Soc. 2003, 125, 11164.

(6) Gierlich, J.; Burley, G. A.; Gramlich, P. M. E.; Hammond, D. M.; Carell, T. Org. Lett. 2006, 8, 3639.

(7) Burley, G. A.; Gierlich, J.; Mofid, M. R.; Nir, H.; Tal, S.; Eichen, Y.; Carell, T. J. Am. Chem. Soc. 2006, 128, 1398.

(8) (a) Saxon, E.; Bertozzi, C. R. Science 2000, 287, 2007. (b) Saxon, E.; Armstrong, J. I.; Bertozzi, C. R. Org. Lett. 2000, 2, 2141. (c) Nilsson, B. L.; Kiessling, L. L.; Raines, R. T. Org. Lett. 2001, $3,9$.
(9) (a) Liu, L.; Hong, Z.-Y.; Wong, C.-H. ChemBioChem 2006, 7, 429. (b) Grandjean, C.; Boutonnier, A.; Guerreiro, C.; Fournier, J.-M.; Mulard, L. A. J. Org. Chem. 2005, 70, 7123. (c) Tsao, M.-L.; Tian, F.; Schultz, P. G. ChemBioChem 2005, 6, 2147. (d) Nilsson, B. L.; Hondal, R. J.; Soellner, M. B.; Raines, R. T. J. Am. Chem. Soc. 2003, 125, 5268. (e) Köhn, M.; Wacker, R.; Peters, C.; Schröder, H.; Soulère, L.; Breinbauer, R.; Niemeyer, C. M.; Waldmann, H. Angew. Chem. Int. Ed. 2003, 42, 5830. (f) Kim, H.; Cho, J. K.; Aimoto, S.; Lee, Y.-S. Org. Lett. 2006, 8, 1149. (g) Watzke, A.; Gutierrez-Rodriguez, M.; Kohn, M.; Wacker, R.; Schroeder, H.; Breinbauer, R.; Kuhlmann, J.; Alexandrov, K.; Niemeyer, C. M.; Goody, R. S.; Waldmann, H. Bioorg. Med. Chem. 2006, 14, 6288. (h) Watzke, A.; Köhn, M.; Gutierrez-Rodriguez, M.; Wacker, R.; Schröder, H.; Breinbauer, R.; Kuhlmann, J.; Alexandrov, K.; Niemeyer, C. M.; Goody, R. S.; Waldmann, H. Angew. Chem. Int. Ed. 2006, 45, 1408.

(10) Wang, C. C. Y.; Seo, T. S.; Li, Z.; Ruparel, H.; Ju, J. Bioconjugate Chem. 2003, 14, 697.

(11) Comstock, L. R.; Rajski, S. R. Nucleic Acids Res. 2005, 33 , 1644.

(12) Comstock, L. R.; Rajski, S. R. J. Am. Chem. Soc. 2005, 127, 14136.

(13) Weisbrod, S. H.; Marx, A. Chem. Commun. 2007, 18, 1828.

(14) Jäger, S.; Rasched, G.; Kornreich-Leshem, H.; Engeser, M.; Thum, O.; Famulok, M. J. Am. Chem. Soc. 2005, 127, 15071.

(15) Gourlain, T.; Sidorov, A.; Mignet, N.; Thorpe, S. J.; Lee, S. E.; Grasby, J. A.; Williams, D. M. Nucleic Acids Res. 2001, 29, 1898

(16) Kahl, J. D.; Greenberg, M. M. J. Am. Chem. Soc. 1999, 121, 597.

(17) (a) Yoshikawa, M.; Kato, T.; Takenishi, T. Bull. Chem. Soc. Jpn. 1969, 42, 3505. (b) Kovács, T.; Ötvös, L. Tetrahedron Lett. 1988, 29, 4525.

(18) (a) Niemeyer, C. M. J. Biotechnol. 2001, 82, 47. (b) Niemeyer, C. M. Trends Biotechnol. 2002, 20, 395. (c) Niemeyer, C. M.; Wacker, R.; Adler, M. Angew. Chem. Int. Ed. 2001, 40, 3169.

(19) Chaudhuri, N. C.; Kool, E. T. J. Am. Chem. Soc. 1995, 117, 10434.

(20) van Ameijde, J.; Liskamp, R. M. J. Org. Biomol. Chem. 2003, $1,2661$. 